\title{
Dynamic characteristics of a spur gear transmission system for a wind turbine
}

\author{
Zhao Xin1, a, Chen Changzheng1, a, Liu Jie1, a, Zhang Lei1, a \\ 1School of Mechanical Engineering, Shenyang University of Technology, Shenyang110870, \\ People's Republic of China
}

azhao.xin.smileface@163.com

Keywords: spur gear, backlash, dynamic characteristics, internal and external excitation

\begin{abstract}
A nonlinear dynamic model of a spur gear transmission system is developed with consideration of gear mesh stiffness, backlash, internal and external excitation. Lagrange equation is used which is derived for the vibration of the drive system differential equations. Time process diagram, frequency spectrum and phase diagram of the spur gear pair system are obtained by using the numerical method. The gear dynamic behaviors are analyzed and the influences of backlash and damping coefficient are given quantitatively. The statistic analysis shows that: the response of the drive system amplitude increases, the enhancement of vibration with the increase of backlash. The solution to the problem provides a reference for inherent characteristic and dynamic response for wind turbine gearbox transmission system.
\end{abstract}

\section{Introduction}

With the increasingly serious energy and environmental problems, wind power in the world scope got rapid development, wind turbines as the core of the wind power system key equipment, the localization of design and manufacture problem become the bottleneck of wind power. In wind turbine, gear drive growth box is a key part. As a result of the gear speed increase and the increase of transmission power, load cases are more and more complex. Performance of gear transmission is also put forward higher requirements. In actual use, about 50 percent of wind generator fault occurs in the gear transmission system [1]. Gear box of high and low reliability and the dynamics characteristics of the fit and unfit quality directly decides the wind turbine can work normally [2]. When gear is at high speed, due to factors such as stiffness, processing and assembling error prone to vibration, thus affecting the transmission system accuracy and stability, it even causes broken teeth destroyed machine and other major accidents. Therefore, studying the dynamics of gear system under various random working condition behaviors is very significant.

For a long time, scholars at home and abroad research on the vibration characteristics of gear system a lot of theoretical analysis and experimental research [3-15]. Kahraman [3] researched such as the various forms by the dynamic response of the gear transmission system. Parker [4] analyzed, such as time-varying mesh stiffness and friction factor, the gear bending, coincidence degree and the change of the modal damping parameters such as the impact on the stability boundary.LIN [5-7] used different methods, such as torsion of the planetary gear transmission dynamics model is established, the nonlinear dynamic response of a planetary gear is analyzed. Chen [8] studied the tooth and clearance of gear dynamic response of the system. Reference [9] by using phase plane trajectory, Poincare mapping, the FFT spectrum meshing stiffness, damping and outer loads and nonlinear effect the properties of the system, the system of periodic, quasi-periodic and chaotic motion. Lu [10] analyzed the clearance as random variables, such as using bifurcation diagram and the largest Lyapunov index and dynamics of gears system configuration are analyzed. BAHK [11], such as gear drive was studied in the analytical solution of the nonlinear dynamics. Wang [12] further studied of the main characteristics of the vibration system parameters. Su Cheng [13] single stage gear system was studied in the frequency response law of parameter changes. Li Fajia [14] centralized, such as quality standard, the nonlinear dynamic equation of planetary gear transmission system is established, and the Runge-Kutta method is adopted to solve the response of the system. 
Liu Zhenhao [15] used IHB method etc contain backlash of fundamental frequency steady state response of the compound planetary gear transmission system, studies the time-varying meshing stiffness, external motivation and the change of the parameters such as backlash effect the dynamics of the system. When the gear transmission system is highly speeding running, using the traditional linear model and linear theory has not reliable to reflect the dynamic behavior of the system. Improvement with vibration theory, considering coupling of nonlinear factors can be reflected the real situation more vibration characteristics of the system.

This paper establishes a large-scale wind turbine gearbox high-speed pure torsion nonlinear dynamic model of gear transmission system, using Lagrange equation derived for the vibration of the drive system differential equations, and it carries on the numerical analysis, the different gear meshing backlashes on the effect of dynamic characteristics of gear transmission system is studied. It can provide the theoretical basis for wind power gear box of spur gear transmission system dynamics.

\section{Nonlinear dynamic model of gear system}

Assuming the gear system of the shafts and bearings are rigid, ignore the sliding friction between the tooth surfaces of gear tooth and set up as shown in Fig.1 a dynamic model of gear pair.

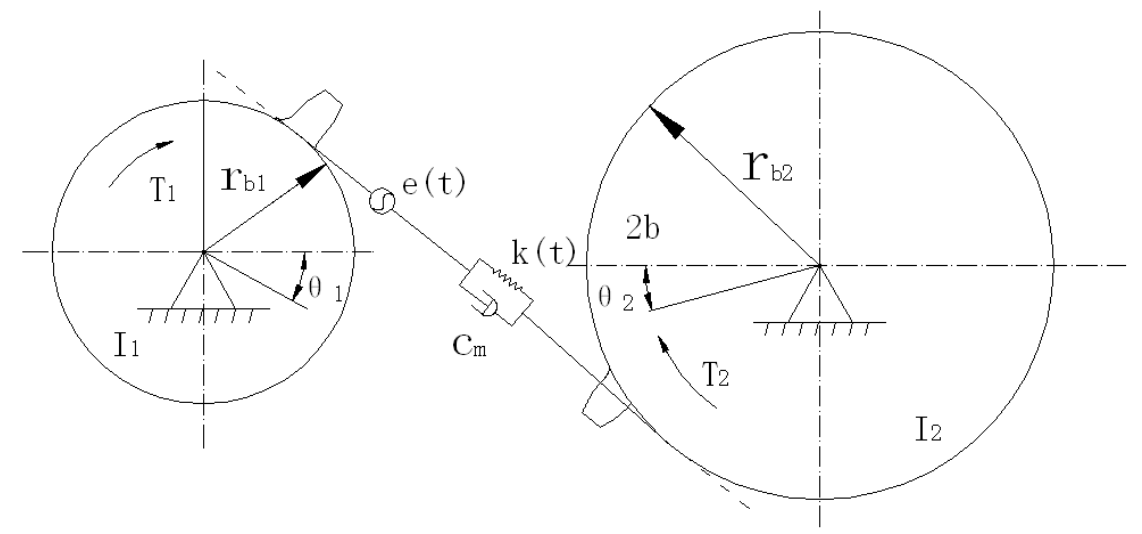

Fig.1: A nonlinear dynamic model of gear transmission system

According to the Lagrange equation derived for a torsion vibration equation of gear system:

$$
\begin{gathered}
I_{1} \ddot{\theta}_{1}+c_{t 1} \dot{\theta}_{1}+k_{t 1} \theta_{1}=T_{1}-r_{b 1} F_{m} \\
I_{2} \ddot{\theta}_{2}+c_{t 2} \dot{\theta}_{2}+k_{t 2} \theta_{2}=-T_{2}+r_{b 2} F_{m}
\end{gathered}
$$

In the function, $I_{1}$ and $I_{2}$ are given priority to the rotational inertias of the driven gear respectively; $r_{b 1}$ and $r_{b 2}$ much-publicized are mainly driven gear base circle radius, inner common tangent of two base circle which is a line of action, with a dotted line; $T_{1}$ and $T_{2}$ are respectively driven gear rotational torque; $\theta_{1}$ and $\theta_{2}$ are primarily driven gear's torsion vibration displacement respectively; $c_{t 1}$ and $c_{t 2}$ are given priority to the viscous damping coefficient of driven gear respectively; $k_{t 1}$ and $k_{t 2}$ are primarily driven gear spring stiffness. $F_{m}$ is gear dynamic meshing force and its expression is

$$
F_{m}=c_{m} \dot{\delta}+k_{m} \delta
$$

Definition $e(t)$ is the tooth meshing error, then

$$
e(t)=e_{m}+e_{r} \sin (\omega t+\varphi)
$$

Where, $e_{m}$ stands for gear meshing error constant; $e_{r}$ stands for gear meshing error amplitude; speed $n_{1}$ and $z_{1}$ are active gear for the driving gear teeth; $\varphi$ stands for the initial phase Angle.

Define $\delta$ is the dynamic transmission error of gear tooth, and then the relative displacement can be expressed as the two gear meshing line:

$$
\delta=r_{b 1} \theta_{1}-r_{b 2} \theta_{2}-e(t)
$$

Reference [16] when the system exits the impacts, which include the double-sided impact and 
single-side impact, the system presents an unstable motion state, otherwise the system lies in a stable state. Single clearance of gear system nonlinear function can be expressed as:

$$
f(\delta)=\left\{\begin{array}{lc}
\delta-\bar{b} & \delta>\bar{b} \\
0 & -\bar{b} \leq \delta \leq \bar{b} \\
\delta+\bar{b} & \delta<-\bar{b}
\end{array}\right.
$$

Put (2) (5) into type (1), it can be written:

$$
\begin{aligned}
& I_{1} \ddot{\theta}_{1}+c_{t 1} \dot{\theta}_{1}+r_{b 1} c_{m}\left(r_{b 1} \dot{\theta}_{1}-r_{b 2} \dot{\theta}_{2}-\dot{e}\right)+ \\
& k_{t 1} \theta_{1}+r_{b 1} k_{m} f\left(r_{b 1} \theta_{1}-r_{b 2} \theta_{2}-e\right)=T_{1} \\
& I_{2} \ddot{\theta}_{2}+c_{t 2} \dot{\theta}_{2}-r_{b 2} c_{m}\left(r_{b 1} \dot{\theta}_{1}-r_{b 2} \dot{\theta}_{2}-\dot{e}\right)+ \\
& k_{t 2} \theta_{2}-r_{b 2} k_{m} f\left(r_{b 1} \theta_{1}-r_{b 2} \theta_{2}-e\right)=-T_{2}
\end{aligned}
$$

Ideally, $c_{\mathrm{m}}$ is the gear pair meshing damping coefficient; $k_{\mathrm{m}}$ is the mesh stiffness of gear pair. Will type (6) further simplify, written as matrix form:

$$
\boldsymbol{M} \ddot{x}+\boldsymbol{C} \dot{x}+\boldsymbol{K} x=\boldsymbol{F}
$$

Where, $\boldsymbol{M}$ as the matrix for system quality, $\boldsymbol{C}$ as the system damping matrix, $\boldsymbol{K}$ as the time-varying stiffness matrix, are 2 order phalanxes, $\boldsymbol{F}$ as the load column.

\section{Nonlinear propulsion system}

Gear system parameters are as follows: Number of gear teeth $Z_{1}=25, Z_{2}=98$; Module of gear $m=6.5 \mathrm{~mm}$; Moment of inertia $I_{1}=0.207 \mathrm{~kg} \cdot \mathrm{m}^{2}, I_{2}=44.355 \mathrm{~kg} \cdot \mathrm{m}^{2}$; Radius $r_{b 1}=0.1 \mathrm{~m}, r_{b 2}=0.4 \mathrm{~m}$; Torsion stiffness $k_{t 1}=0.254 \times 10^{6}(\mathrm{~N} \cdot \mathrm{m} / \mathrm{rad}), k_{t 2}=4.027 \times 10^{6}(\mathrm{~N} \cdot \mathrm{m} / \mathrm{rad})$; Tensional damping $c_{t 1}$, $c_{t 2}=5.0 \times 10^{2}(\mathrm{~N} / \mathrm{rad} / \mathrm{s})$; Meshing damping coefficient $c_{m}=8.0 \times 10^{2}(\mathrm{~N} /(\mathrm{m} / \mathrm{s}))$; the meshing stiffness $k_{m}=6.0 \times 10^{6}(\mathrm{~N} / \mathrm{m})$; Error mean $e_{m}=2.0 \times 10^{-5} \mathrm{~m}$; Error fluctuation $e_{r}=3.0 \times 10^{-5} \mathrm{~m}$. Torque mean $T_{1}=100 \mathrm{~N} / \mathrm{m}, T_{2}=300 \mathrm{~N} / \mathrm{m}$. Considering the gear side clearance, meshing damping coefficient as nonlinear factors, using numerical method to solve the above formula, the gear system time domain waveform, spectrum response and phase diagram were given.

Non-backlash is usually adopted in gear design, while backlash always exits and is generally shown as non-linearity in consideration of manufacture error and so on. Gear system backlash changes will seriously affect the dynamic response of the system. When backlash increase gradually, the response amplitude is decreased obviously. When the backlash gear is under the condition of different parameters, the gear system will have three completely different states: the state of shock, impact unilateral and bilateral impact state. For backlash is $2 \times 10^{-5} \mathrm{~m}$, the time process diagram, frequency spectrum and phase diagram of gear system are shown in Fig.2.For backlash is $3.2 \times 10^{-5} \mathrm{~m}$, the time process diagram, frequency spectrum and phase diagram of gear system can be seen from Fig.3. When backlash is $8.8 \times 10^{-5} \mathrm{~m}$, the time process diagram, frequency spectrum and phase diagram of gear system can be seen from Fig.4. As a result, the existence of backlash for gear wheel contact state has changed; the gear pair shows non-linear vibration characteristics. Backlash changes affecting the behavior of the dynamics of gear system, when the gear side clearance between increases gradually, the vibration amplitude of the gear system will increase. At the same time, the backlash increases, the nonlinear system response becomes less. When the backlash decreases, the nonlinear system response becomes more prominent. 


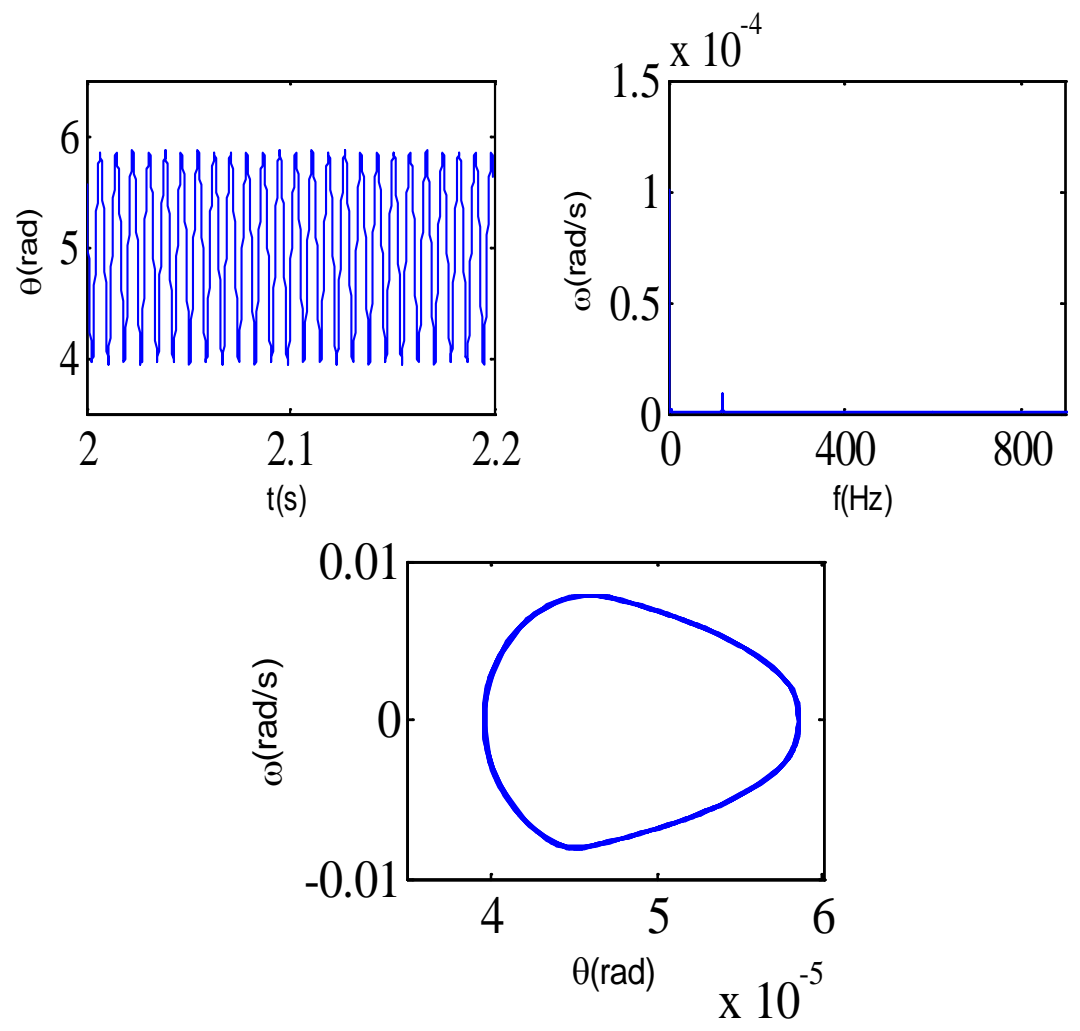

Fig.2: The time process diagram, frequency spectrum and phase diagram of gear System
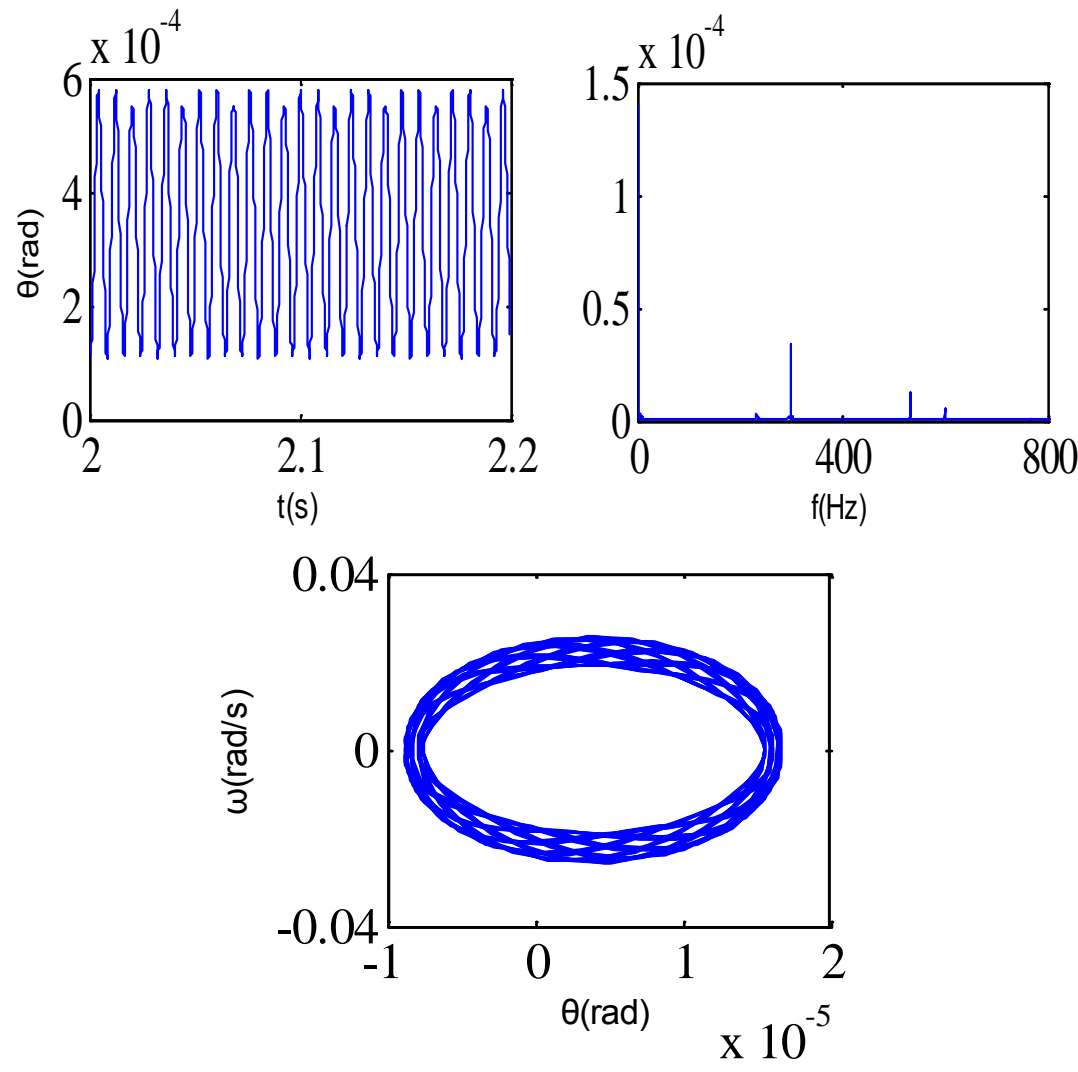

Fig.3: The time process diagram, frequency spectrum and phase diagram of gear System 

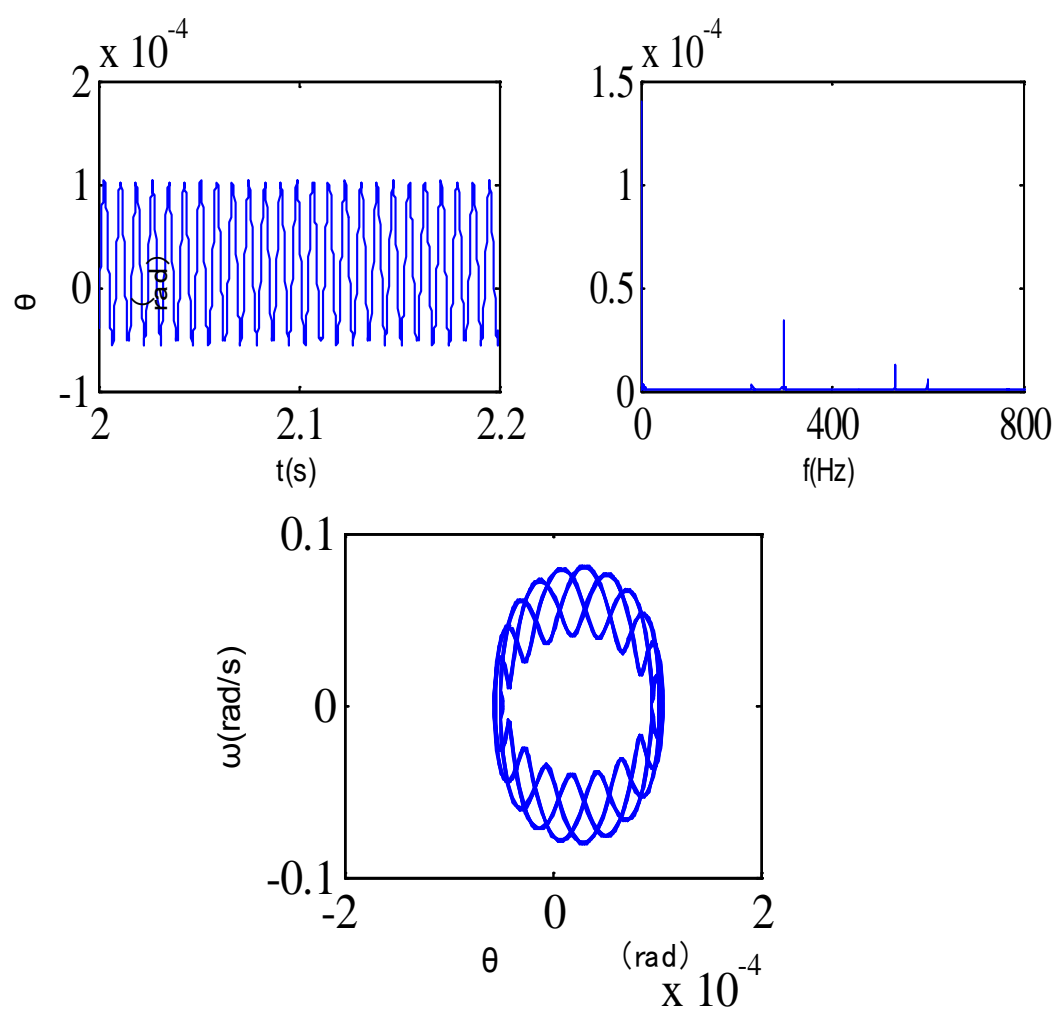

Fig.4: The time process diagram, frequency spectrum and phase diagram of gear system

\section{Conclusion}

Large wind turbine gearbox transmission system is presented in this paper, the high-speed level straight pure torsion nonlinear dynamic model of gear transmission, application of Lagrange equation is derived for the vibration of the drive system differential equations. By changing different backlash, using the numerical method, gear transmission system nonlinear vibration characteristics and the system vibration response are comparative analyzed. The results show that with the increase of mesh backlash, the transmission system of the response amplitude increases obviously and the vibration of the drive system. It provides the basis of dynamic response characteristics for the intrinsic characteristics of wind power gear box drive system. Moreover, the decrease of the backlash could effectively control the nonlinear vibration of spur gear system. The study result offers a reference for gear system design and fault diagnosis. The solution to the problem provides a reference for inherent characteristic and dynamic response for wind turbine gearbox transmission system.

\section{References}

[1] Qin Datong, Xing Zikun, Wang Jianhong, etc. Optimization design of system parameters of the gear transmission of wind turbine based on dynamics and reliability [J]. Journal of Mechanical Engineering, 2008, 30 (12): 1-6.

[2] Qiu Xinghui, Han Qinkai, Chu Fulei. Wind turbine planetary gear transmission system dynamics research review [J]. Journal of mechanical engineering, 2014, 50 (11): 23-36.

[3] Kahraman A, Singh R. Non-linear dynamics of a spur gear pair [J]. Journal of Sound and vibration, 1990, 142(1): 49-75.

[4] Liu G, Parker R G. Impact of tooth friction and its bending effect on gear dynamics [J]. Journal of Sound and Vibration, 2009, 320(4): 1039-1063.

[5] Lin J, Parker R G. Analytical characterization of the unique properties of planetary gear free vibration [J]. Journal of Vibration and Acoustics, 1999, 121(3): 316-321.

[6] Parker R G, Agashe V, Vijayakar S M. Dynamic response of a planetary gear system using a 
finite element/contact mechanics model [J]. Journal of Mechanical Design, 2000, 122(3): 304-310.

[7] Lin J, Parker R G. Planetary gear parametric instability caused by mesh stiffness variation [J]. Journal of Sound and vibration, 2002, 249(1): 129-145.

[8] Chen Siyu, Tang Jinyuan. Effect of backlash on dynamics of spur gear pair system with friction and time-varying stiffness [J]. Journal of Mechanical Engineering, 2009, 45(8): 119-124.

[9] Chang-Jian C W. Nonlinear analysis for gear pair system supported by long journal bearings under nonlinear suspension [J]. Mechanism and Machine Theory, 2010, 45(4): 569-583.

[10] Lu Jianwei, Zeng Fanling, Yang Hansheng, etc. Influence of stochastic assembling backlash on nonlinear dynamic behavior of transmission gear pair [J]. Journal of Mechanical Engineering, 2010, 46 (21): 82-86.

[11] BAHK C J, PARKER R G. Analytical solution for the nonlinear dynamics of planetary gears [J]. Journal of Computational and Nonlinear Dynamics, 2011, 6(2): 1-15.

[12]Wang Jianjun, Han Qinkai, Li Qihan. Parameters of vibration system frequency response characteristic research [J]. Journal of vibration and shock, 2010, 29 (3): 103-108.

[13]Su Cheng, Yin Pengpeng. Gear system nonlinear dynamics analysis [J]. China mechanical engineering, 2011, 22 (16): 1922-1928.

[14]Li Fajia, Zhu Rupeng, Bao Heyun, etc. Planetary gear train dynamics analysis and test study [J]. Journal of Nanjing university of aeronautics and astronautics, 2012, 44 (4): 511-519.

[15]Liu Zhenhao, Wu Shijing, Wang Xiaosun, etc. Based on the incremental harmonic balance method of compound planetary gear system nonlinear dynamics [J]. Journal of vibration and shock, 2012, 31 (3): 117-122.

[16]Lin Tengjiao, Wang Danhua, Ran Xiongtao et.al. Coupled nonlinear vibration analysis of multi-stage gear transmission system [J]. Journal of Vibration and shock, 2013, 32(17): 1-8. 